\title{
The Study on the Effectiveness of a Learning Ability Improvement Program for Low Achieving College Students
}

\section{학업 저성취 대학생을 위한 학습력 향상 프로그램의 효과성 분석 연구}

Youngran Yoon $^{1}$

윤영란 1

${ }^{1}$ Professor, College of Liberal Arts, Seokyeong University, Korea, yoon1112@skuniv.ac.kr

\begin{abstract}
The purpose of this study is to analyze the effectiveness of the learning ability improvement program for low achieving students operated by the Teaching and Learning Support Center for students with low academic performance in college. The subjects of this study were 16 college students who applied for the learning ability improvement program for low achieving students at S University's Teaching and Learning Support Center in Seoul. The learning ability improvement program was a total of 8 sessions and was conducted every 50 minutes each week. Students who participated in the program were students who had difficulty in college learning with an average grade point of less than 3.0 in the previous semester. The effectiveness of the program was analyzed by self-directed learning ability test. As a result of the study, it can be seen that the self-directed learning ability of college students who participated in the learning ability improvement program for low achieving college students improved overall, and thus their learning ability was improved. In other words, it is revealed that the program is highly effective in improving the learning ability that learners can voluntarily lead the entire process of university learning. However, the continuity part of the learning execution area did not show a significant improvement. In the case of low-achieving students, it suggests that there is a need for a way to keep learning after completing the program. Based on these research results, specific suggestions were made on the development and operation of learning support program for underachieving students who are struggling with academic difficulties in college.
\end{abstract}

Keywords: College Students, Low Achieving Students, Learning Ability Improvement Program, SelfDirected Learning Ability Test

요약: 본 연구의 목적은 대학에서 학업부진으로 어려움를 겪고 있는 학생들을 위하여 교수학 습지원센터에서 운영한 학업 저성취 학생 대상의 학습력 향상 프로그램의 효과성을 분석하는 것이다. 연구의 대상은 서울소재 S 대학 교수학습지원센터 학업 저성취 학생을 위한 학습력 향상 프로그램에 지원한 16 명의 대학생이다. 학습력 향상 프로그램은 총 8회기의 프로그램으 로 50분씩 매주 진행하였다. 프로그램에 참여한 학생은 직전 학기 평균 학점이 3.0 미만이면 서 대학학습에 어려움을 겪고 있는 학생으로 자발적인 참여로 이루어졌으며 프로그램의 효과 성은 자기주도적 학습능력 검사로 분석하였다. 연구의 결과 학업 저성취 대학생을 대상으로 한 학습력 향상 프로그램에 참여한 학생들의 자기주도적인 학습능력이 전반적으로 향상되었

Received: June 01, 2021; $1^{\text {st }}$ Review Result: July 17, 2021; $2^{\text {nd }}$ Review Result: September 02, 2021

Accepted: October 31, 2021 
다. 학습의 전과정을 학습자가 자발적으로 이끌어 갈 수 있는 학습력을 향상시키는데 프로그 램의 효과가 높게 나타났다. 그러나 학습실행영역 중 지속성 부분은 유의미한 향상을 나타내 지 않았다. 따라서 학업 저성취학생들을 대상으로 하는 경우 프로그램 이수 후 지속적으로 학습을 유지할 수 있는 지원 방안이 필요하다. 이러한 연구 결과들을 토대로 대학에서 학업 부진으로 어려움을 겪고 있는 학업 저성취 대학생을 위한 교육적 제언을 하였다.

핵심어: 대학생, 학업 저성취 학생, 학습력 향상 프로그램, 자기주도적 학습능력 검사

\section{1. 서론}

최근에는 학력인구의 감소와 청년실업문제가 심각해지면서 대학교육의 질 개선이 무엇보다 중요하게 강조되고 있다. 학습자중심의 교육과 대학교육의 지속적인 질 개선이 요구되는 시점에서 대학에서는 잘 가르치기 위한 교육역량을 높이고 그에 따른 학생들의 학업성취를 높이고자 많은 노력을 기울이고 있다.

현재 대학들은 학생들의 학업성취를 높이고 중도탈락이 발생하지 않도록 다양한 노력들을 하고 있으나 이를 위해서는 무엇보다 학업 저성취자에 대한 체계적인 관리가 필요하다. 각 대학에서 이루어지고 있는 학업 저성취 학생에 대한 관리는 대부분이 학사경고자 관리이며 학사경고자 관리도 사전 예방보다는 사후 관리 방안을 마련하고 다양한 학습지원 프로그램을 운영을 통하여 학사경고자가 발생하지 않도록 하는데 초점이 맞추어져 있다. 그러나 학사경고는 사후관리보다는 예방이나 지원의 차원에서 접근하는 것이 바람직하며 학사경고가 발생하지 않도록 하기 위해서는 무엇보다 학사경고가 발생하기 이전의 학업 저성취학생들에 대한 철저한 관리와 지원이 중요하다. 그 이유는 학사경고가 학업 저성취 또는 학업부진과 중도탈락과 직접적으로 연계되어 있기 때문이다[1].

학업 저성취 학생들에게 대한 관리와 지원을 위해서는 무엇보다 학업 저성취 학생들의 자기주도적인 학습능력을 높이기 위한 노력이 필요하다. 대학에서 이루어지는 대부분의 학습은 자율성을 기반으로 한 자기주도학습으로 이루어진다. 학습의 주도성을 가지고 스스로 학습목표를 설정하고 계획을 수립한 뒤 실행해 나가면서 부딪히는 소소한 문제들을 극복하는 능력이 학업성취에 직접적인 영향을 미친다. 그러나 우리나라의 경쟁적 입시를 치르고 대학에 진학한 학생들은 자신의 적성이나 흥미보다는 수능성적이나 내신등급에 따라 대학이나 전공을 선택함으로써 학교생활의 흥미나 동기의 부족으로 대학생활에 적응하지 못하고 학사경고자가 되기도 한다.

따라서 학업 저성취학생들에게는 학생들 스스로가 자신의 학습에 대한 목표를 세우고 목표를 달성하기 위한 자기주도적인 학습능력이 무엇보다 필요하다. 자기주도적인 학습능력은 학습자가 자신의 학습에 대한 주도권을 가지고, 자신의 학습욕구를 진단하여 학습목표를 설정하고 학습에 필요한 인적 · 물적 자원을 확보하고, 적합한 학습전략을 선택 - 실행하며 자신이 성취한 학습결과를 스스로 평가하는 과정을 포괄한다[2]. 학생 개개인의 학업성취를 높여 대학학습을 성공적으로 마치는데 매우 중요한 능력이다.

따라서 본 연구에서는 학업 저성취 학생들을 대상으로 자기주도적인 학습 능력을 증진시키기 위한 학습력 향상 프로그램을 운영하고 그 효과성를 분석하여 학업 저성취 대학생들을 위한 학습적인 지원에 대한 제언을 하고자 한다. 


\section{2. 이론적 배경}

\section{1 학업 저성취 대학생 개념}

학업 저성취는 학업부진과 자주 혼용되어 사용하는 용어로서, 일반적으로 학생의 지적능력에 의해 예측할 수 있는 학업성취에 비해 현저하게 낮은 성취를 보이는 것을 학업부진(under achievement) 이라 하고, 집단 내에서 상대적으로 낮은 학업성취를 보이는 것을 학업저성취(low achievement)라고 한다[1]. 정상적인 학교생활을 할 수 있는 잠재능력에 비해 학업 성취수준이 낮은 현상을 의미하며, 선수학습의 부족, 낮은 학습동기, 학업적 지지가 어려운 가정환경과 같은 이유로 발생하는 학업적인 문제로 볼 수 있다.

대학생의 경우는 이미 대학에 입학한 것으로도 어느 정도의 인지적 능력을 가지고 있다고 판단되므로 학업부진보다는 학업 저성취라는 개념이 더 적합하다. 학업 저성취가 발생하는 원인은 학교생활을 할 수 있는 인지적 능력은 있으나 불충분한 선수학습이나 낮은 학습동기 혹은 가정환경 및 교육적으로 충분히 도전적이지 못한 학교 학습환경으로 인해 발생한다고 밝히고 있다[1][3]. 대학에서의 학업 저성취자는 일반적으로 집단 내에서 상대적으로 높은 학업성취를 달성할 수 있는 능력이 있음에도 불구하고 학업성취가 낮은 학습자를 의미하는데 이는 낮은 학점을 받은 학생이라고 할 수 있다. 대부분의 선행연구에서는 평균 평점이 3.0 이하에 속한 학생들을 의미하고 있다[3].

\section{2 학업 저성취 대학생의 특징}

학업 저성취 대학생들의 특징은 학사경고자나 학업부진 학생들과 혼용되면서 학사경고자 대학생들의 특징과 비슷하게 특징지어지고 있다. 밝혀진 연구결과들을 살펴보면, 학사경고의 원인은 낮은 학습 동기, 대학과 전공 불일치, 대학과 전공에 대한 실망감, 스트레스 관리실패, 낮은 학업적 자기효능감, 대인관계 문제, 대학학습방법의 어려움, 시간 관리 실패 등으로 나타났다[4-8].

학사경고자 및 학업 저성취자의 특성 분석으로 밝혀진 공통된 특징은 낮은 학습동기였다. 학습동기는 기대되는 미래목표와 가치를 위해 방향성과 목적을 가진 행동을 시작하게 하고 지속하는 힘으로 정의된다. 따라서 학사경고자를 위한 개입활동 중 가장 효과적인 지원은 삶의 목표와 학습에 대한 목표를 설정하는 것이라고 할 수 있다.

학업 저성취 대학생들은 일반적으로 학습동기와 자기효능감이 낮으며 스트레스 혹은 불안에 취약한 편이라고 보고하고 있으며 과제나 시험 등의 학습하는 시간과 노력도 부족하고 시간계획 및 관리에 미숙하며 자기조절이나 자기주도학습능력이 낮은 것으로 밝히고 있다[5][6]. 결석이나 지각이 잦을 뿐 만 아니라 대학학습에 대한 성공적인 학습을 지지해 줄만한 가정 환경이나 학교 환경을 가지지 못한 경우도 있으며 학습전략을 효율적으로 사용하는데도 미숙한 것으로 나타났다[5-7].

\section{3 대학생 학업 저성취 요인}

대학생 학업 저성취에 영향을 미치는 요인은 부모의 기대수준과 양육태도, 경제적 문제, 장거리 통학시간 등 개인적 요인과 환경적 요인 등 다양한 요인들이 상호작용하고 
있다[8]. 대부분의 선행연구에서는 대학생 학업 저성취 요인을 목표 설정 부재, 학습 의지 부족, 낮은 학습 동기, 전공이나 학교에 대한 불만족, 기초 학습 능력 부족, 학습 전략 부족, 성적 관리 능력 부족, 수업 방식 부적응, 시간 관리 부족, 대인 관계 부족, 심리/건강 문제, 학과/학생회 활동 부적응 등 다양한 요인으로 인해 발생하는 것으로 밝히고 있다[4-7].

대학에서 이루어지는 학습은 학습자의 자기주도성을 기반으로 이루어진다. 자기주도적인 학습능력은 스스로 학습목표를 설정하고 이를 실행해나가는 능력으로 학업성취에 절대적인 영향을 미친다. 따라서 대학생들의 학업성취를 높이기 위해서는 자기주도학습능력을 향상 시킬 수 있는 학습력 향상 프로그램이 대학 차원에서 개발되고 운영될 필요가 있다.

\section{4 학업 저성취 대학생 학습지원 관련 선행연구}

대학에서는 학업 저성취 대학생들을 위한 다양한 학습지원 프로그램 운영하고 있다. 과거에는 학사경고자 사후 관리 프로그램의 운영을 통하여 학사경고자를 관리하였으나 최근에는 학사경고 예방이 더 중요하게 대두됨에 따라 대학생들의 학업문제에 실질적으로 도움을 주고 학업 저성취학생들에 대한 체계적인 관리가 중요해 지고 있다.

대학생 학업 저성취 대상 학습지원 프로그램은 주로 학습법지원, 학습상담, 학습컨설팅, 학습전략검사, 멘토프로그램, 기초학습지원 등 다양한 주제로 프로그램이 운영되고 있다.

대학에서 학업 저성취 학생들을 위한 학습지원은 다음의 세 가지 영역으로 구분할 수 있다.

첫째, 대학학습에 필요한 학습법 지원이다. 각 대학의 교수학습지원센터에서는 대학생들에게 필요한 보고서작성, 노트필기, 시간관리, 집중력 등 다양한 학습전략 프로그램을 운영하고 있다. 학사경고자 혹은 학업 저성취 대학생들을 대상으로 하는 대부분의 학습지원 프로그램은 학사경고원인 분석을 통한 프로그램의 개발 및 운영, 학습동기향상 프로그램, 자기탐색 프로그램. 스트레스 대처전략 프로그램, 시간관리 프로그램 등 다양한 프로그램을 통하여 학업 저성취자 대학생들의 학습을 지원하고 있다. 학업 저성취자를 위한 프로그램의 효과성 연구 결과는 대부분이 자기결정성 및 스트레스 대처수준을 향상시키는데 효과가 있으며 학습동기, 자기효능감 등에서 유의미한 향상을 보고하고 있다[8-10].

둘째, 학사경고자 혹은 학업 저성취 대학생들을 위한 교과목을 개설하여 이수하도록 하는 학습지원이다. 일부 대학에서는 학사경고자를 대상으로 교양교과목을 개설하여 이수하게 함으로써 학업에 도움을 주기도 하고 Northeastern University에서는 학사경고자 235 명에게 시간관리와 평가전략 등을 포함한 학습전략 온라인 강좌로서 '학업성공교과목(Academic Success)' 를 이수하도록 한 결과 학업성적이 향상되고 재학율도 높아졌다고 선행연구에서 밝히고 있다[11].

셋째, 프로그램 보다는 전문연구원과의 $1: 1$ 학습상담이나 학습컨설팅을 통한 맞춤형 학습지원이다. 개별 학생들의 $1: 1$ 학습상담 및 학습컨설팅 지원은 동료나 멘토로부터 받는 정서적 지원과 심리적 안정에 해당하는 것으로 학업 저성취자들의 학업 성취 및 성적 향상에 긍정적인 효과를 준 것으로 보고되고 있다. 학사경고자 혹은 학업 저성취 대학생들 중 5 회기 이상 지속적 상담 참여 경험은 학업성취도를 향상시켰다고 일관성이 
있게 밝히고 있다[8-10].

넷째, 학업 저성취 학생들을 위한 기초학습지원 프로그램의 운영이다. 대학학습에 필요한 기초수학, 기초영어, 글쓰기 능력을 향상시키기 위한 프로그램을 운영하여 기초학력 부족의 문제를 해결하기 위해 노력하고 있다. 특히 이공대 학생들을 위한 수학 및 과학 관련 기초학습지원 프로그램은 보충학습개념으로 일대일 밀착지원의 형태로도 이루어지고 있다[4-10].

\section{3. 연구방법}

\section{1 연구설계 및 절차}

본 연구에서는 학업 저성취 대학생을 위한 학습력 향상 프로그램의 효과를 분석하는 실행연구(action research)방법을 사용하였다. 실행연구의 원리를 바탕으로 대학에서 학업에 어려움을 겪고 있는 학업 저성취 학생들을 위한 프로그램을 개발하고 그 효과성을 검증하였다. 선행연구에서 밝혀진 대학생 학업 저성취 요인을 중심으로 학습력 향상 프로그램의 내용을 구성하였으며 프로그램은 매주 50 분씩 총 8회기로 운영하였다. 프로그램의 주요 구성 요인은 목표설정, 학습의지. 학습동기. 학습전략, 성적관리. 시간관리 등의 주제로 운영하였다. 프로그램 시작 전에 학업 저성취 대학생들과 사전미팅을 통하여 대학학습에서 어려움을 겪는 부분과 자신 만의 학습문제에 대하여 개별적인 상담을 진행하였으며 개별 학습스타일 검사를 통해 자신의 학습스타일에 대한 전반적인 정보를 제공해 주었다.

학업 저성취 학생들을 대상으로 한 학습력 향상 프로그램의 운영 성과를 높이기 위하여 성실히 참여할 것을 서면으로 약속받았다.

본 연구의 진행과정은 다음의 [그림 1]과 같다.

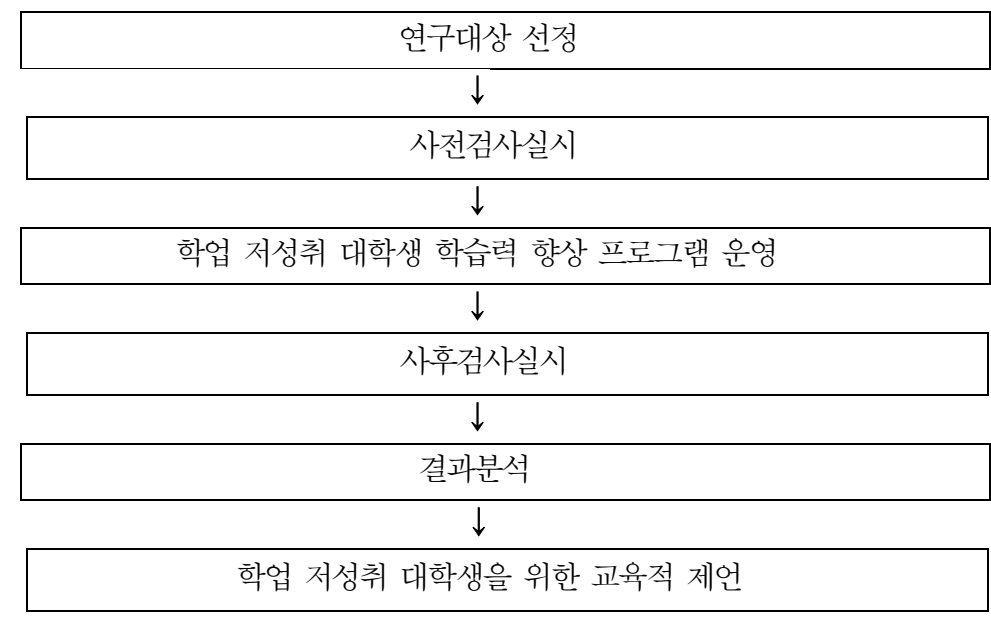

[그림 1] 연구 진행 과정

[Fig. 1] Research Process

학업 저성취 대학생을 위한 학습력 향상 프로그램의 구체적인 내용은 다음의 [표 1]와 같다. 학습력 향상 프로그램은 학업 저성취에 영향을 미치는 요인들로 구성하였다. 
목표설정, 학습의지. 학습동기. 학습전략, 성적관리. 시간관리 등 자기주도적인 학습능력을 향상하여 전반적인 학습력을 향상하고자 하였다.

[표 1] 학업 저성취 대학생 대학 학습력 향상 프로그램의 내용

[Table 1] Contents of Learning Ability Improvement Program for Low Achieving Students

\begin{tabular}{|c|c|}
\hline 회기 & 프로그램 세부 내용 \\
\hline 1차 & $\begin{array}{c}\text { 학습스타일 파악하기(MLST 학습전략 검사 실시) } \\
\text { 학습의 강점과 약점 파악하기 } \\
\text { 학습의 목표 구체적으로 정하기 }\end{array}$ \\
\hline 2차 & $\begin{array}{l}\text { 대학학습의 어려움 의견 교환, 학업 부진의 원인 분석 } \\
\text { 자기주도학습능력진단 및 자신의 학습역량 파악하기 }\end{array}$ \\
\hline 3차 & $\begin{array}{c}\text { 동기부여 전략법, 외재적 혹은 내재적 동기유발방법 } \\
\text { 자기효능감 높이기 } \\
\text { 학습동기 유발하기 위한 방법 익히기 }\end{array}$ \\
\hline 4 차 & $\begin{array}{c}\text { 성공적인 대학학습을 위한 학습방법 } \\
\text { 자신의 정서특성 극복하기 } \\
\text { 우울, 불안, 스트레스 해소 방법 }\end{array}$ \\
\hline 5 차 & $\begin{array}{c}\text { 보고서작성법, 노트필기전략, 집중력 강화법, } \\
\text { 암기법, 레포트 작성법 } \\
\text { 기억력강화법, 기억전략 익히기 }\end{array}$ \\
\hline 6차 & $\begin{array}{c}\text { 성적관리 혹은 시험관리 방법, } \\
\text { 시험전략, } \\
\text { 시험지 작성 방법 연습하기 }\end{array}$ \\
\hline 7차 & $\begin{array}{l}\text { 자신의 학습환경 바꾸기, } \\
\text { 학습환경 만드는 방법 익히기, } \\
\text { 집중력 방해요소 제거하기 }\end{array}$ \\
\hline 8차 & $\begin{array}{l}\text { 시간관리, 미루는 습관 바꾸기. } \\
\text { 성공적인 팀플 활동 노하우, } \\
\text { 자신의 행동특성 점검 하기 }\end{array}$ \\
\hline
\end{tabular}

\section{2 연구대상 및 방법}

본 연구의 대상은 교수학습지원센터 주관의 학업 저성취 대학생들을 위한 학습력 향상 프로그램에 참여한 대학생 16 명이다. 프로그램에 참여한 학생은 직전 학기 평균 학점이 3.0 미만이면서 대학학습에 어려움을 격고 있는 학생으로 교수학습지원센터에서 운영하는 학습프로그램에 자발적으로 참여한 학생이다.

학업 저성취 대학생을 위한 학습력 향상 프로그램은 총 8회기의 집단프로그램으로 매주 50분씩 총 8주간 진행하였다. 프로그램의 효과성 분석은 자기주도적 학습능력 척도로 분석하였다.

\section{3 자료수집 및 분석}

본 연구에서는 학업 저성취자 대학생을 학습력 향상 프로그램의 효과성을 측정하기 위해 이석재, 장유경, 이현남, 박광엽(2003)이 개발한 자기주도적 학습능력 척도를 
사용하였다.

자료분석은 SPSS 21.0 프로그램을 활용하였으며 수집된 자료의 신뢰도 분석을 실시하였다.

자기주도적 학습능력 척도는 학습계획, 학습실행, 학습평가의 3 영역으로 구분되어 있으며 '학습계획' 의 경우, 하위영역인 학습욕구와 목표설정, 학습자원파악으로 구성되어 있으며 '학습실행' 의 경우는 하위영역인 자기관리능력과 학습전략선택, 지속성으로 구성되어 있다. '학습평가' 의 경우, 하위영역은 노력귀인, 자기성찰로 구성되어 있다. 학습욕구 10 문항, 목표설정 5 문항, 학습자원파악 5 문항, 자기관리능력 5 문항, 학습전략 5 문항, 학습실행의 지속성 5 문항, 결과에 대한 노력귀인 5 문항, 자기성찰 5 문항 총 45 문항으로 구성된다. 각 문항은 5 점 Likert 척도를 사용했고 점수가 높을수록 자기주도 학습능력이 높은 것을 의미한다. 본 연구에서 Cronbach's a 값은 학습계획 .71 , 학습실행 .68 , 학습평가 $=.77$ 이었다.

\section{4. 연구결과}

\section{1 학업 저성취 대학생의 학습력 향상 프로그램의 결과 분석}

학업 저성취 대학생 대상 학습력 프로그램의 효과는 자기주도적 학습능력의 향상 여부로 검증하였다. 분석한 결과, 프로그램에 참여한 학생들의 자기주도학습능력이 전반적으로 향상되었다. 다만 자기주도학습능력 학습실행 영역 중 지속성 부분은 유의미한 향상을 보이지 않았는데 이 영역을 제외하고는 모든 하위영역에서 효과가 있는 것으로 나타났다. 사전/사후 결과를 비교해 보면 다음의 [표 2]와 같다.

‘학습계획' 의 경우, 하위영역인 학습욕구와 목표설정, 학습자원파악 모든 영역에서 유의미한 향상을 나타냈다. 학습욕구는 $\mathrm{M}=3.15(\mathrm{SD}=.42)$, 목표설정은 $\mathrm{M}=3.13(\mathrm{SD}=.50)$, 학습자원파악은 $\mathrm{M}=3.22(\mathrm{SD}=.43)$ 으로 모두 통계적으로 유의미하였다. 즉 학업 저성취 학생들은 학습력 향상 프로그램을 통하여 자신의 학습욕구를 이해하고 학습목표를 설정하며 자신이 가진 학습자원을 더 잘 파악한 것으로 볼 수 있다.

‘학습실행’ 의 경우도 하위영역인 자기관리 능력과 학습전략 선택에서 유의미한 향상을 나타냈다. 그러나 지속성의 경우는 유의미한 향상 점수를 보여주고 있지 않아 학업저성취학생들을 대상으로 한 학습력 향상 프로그램으로 학습을 지속적으로 유지하는 데는 큰 도움을 주지 못한 것으로 볼 수 있다.

'학습평가' 의 경우, 하위영역인 노력귀인, 자기성찰 부분에서 모두 통계적으로 유의미한 향상을 보여주고 있다. 사후점수는 각각 $\mathrm{M}=3.05(\mathrm{SD}=.47), \quad \mathrm{M}=3.03(\mathrm{SD}=.53)$ 로 모두 통계적으로 유의미하였다.

결론적으로 학업 저성취 대학생을 대상으로 한 학습력 향상 프로그램에 참여한 대학생들의 자기주도적인 학습능력이 전반적으로 향상되었다고 볼 수 있다. 즉 대학학습의 전과정을 학습자가 자발적으로 이끌어 갈 수 있는 학습력을 향상시키는데 프로그램의 효과가 높게 있는것으로 나타났다. 그러나 학습실행영역 중 지속성 부분은 유의미한 향상을 나타내지 않고 있어 학업 저성취학생들을 대상으로 하는 경우 프로그램 이수 후 지속적으로 학습을 관리해주고 멘토역할을 해 줄 조력자가 필요함을 시사하고 있다. 외부협력기관의 연계 지원이나 전공학습에 도움을 받을 수 있도록 튜터링 프로그램과 연계해 주는 등 지속적으로 관리해 주는 프로그램이 필요하다. 
[표 2] 학업 저성취 대상 학습력 증진 프로그램의 사전/사후 결과 비교

[Table 2] Compare Results of Learning Ability Improvement Program for Low Achieving Students

\begin{tabular}{ccccccc}
\hline \multirow{2}{*}{ 자기주도적 학습능력 } & \multicolumn{2}{c}{ 사전 $\mathrm{M}(\mathrm{SD})$} & \multicolumn{2}{c}{ 사후 $\mathrm{M}(\mathrm{SD})$} & $\mathrm{t}$ \\
\hline & 학습욕구 & 2.83 & $(0.48)$ & 3.15 & $(0.42)$ & $-4.61^{* * *}$ \\
\cline { 2 - 6 } 학습계획 & 목표설정 & 2.77 & $(0.49)$ & 3.13 & $(0.50)$ & $-3.78^{* *}$ \\
\cline { 2 - 6 } & 학습자원파악 & 2.97 & $(0.65)$ & 3.22 & $(0.43)$ & $-3.78^{* *}$ \\
\hline \multirow{2}{*}{ 학습실행 } & 자기관리능력 & 2.72 & $(0.58)$ & 3.03 & $(0.55)$ & $-3.24^{* *}$ \\
\cline { 2 - 6 } & 학습전략선택 & 2.49 & $(0.63)$ & 2.79 & $(0.56)$ & $-2.71^{*}$ \\
\cline { 2 - 6 } & 지속성 & 2.79 & $(0.47)$ & 2.90 & $(0.34)$ & -1.88 \\
\hline \multirow{2}{*}{ 낙습평가 } & 녁귀인 & 2.66 & $(0.41)$ & 3.05 & $(0.47)$ & $-2.78^{*}$ \\
\cline { 2 - 6 } & 자기성찰 & 2.52 & $(0.44)$ & 3.03 & $(0.53)$ & $-3.14^{* *}$ \\
\hline
\end{tabular}

\section{5. 결론 및 제언}

\section{1 결론}

본 연구에서는 대학생들의 학업성취를 높이고 학사경고자가 발생하지 않도록 학업 저성취학생들을 위한 학습력 향상 프로그램을 자기주도적인 학습능력을 향상시키는데 필요한 요인들로 구성하여 운영하고 그 효과성를 분석하고자 하였다. 연구의 결과는 다음과 같다.

대학생 학업 저성취 대학생을 대상으로 한 학습력 향상 프로그램에 참여한 학생들의 자기주도학습능력이 전반적으로 향상되었다. 학습계획, 학습실행, 학습평가에 이르는 전반적인 학업과정을 학습자가 자발적으로 이끌어갈 수 있는 역량을 강화시켰다. 학업 저성취 학생들은 학습력 향상 프로그램을 통하여 자신의 학습욕구를 더 잘 이해하고 학습목표를 설정하는데 필요한 역량을 향상시키며 자신이 가진 학습자원을 더 잘 파악하였다. 학습을 실행하는데 있어서도 자기관리능력을 향상시키고 자신에게 적절한 학습전략을 선택하는데 있어서의 역량도 향상되었다.

그러나 학습을 지속하는데 필요한 역량은 향상되지 않았다. 학습을 지속적으로 유지하는데 학습력 프로그램을 큰 도움을 주지는 못한 것이라고 볼 수 있다.

'학습평가' 하는 영역에서도 자신의 노력에 대한 귀인을 인정하고 자신의 학습에 대한 자기성찰을 기회가 되었음을 보여주고 있다.

결론적으로 학업 저성취 대학생을 대상으로 한 학습력 향상 프로그램이 대학생들의 자기주도적인 학습능력을 향상시켰다고 할 수 있다. 즉 대학학습의 전과정을 학습자가 자발적으로 이끌어 갈 수 있는 자기주도학습능력을 향상시키는데 프로그램의 효과가 높게 있음을 밝히고 있다. 그러나 학습실행영역 중 지속성 부분은 유의미한 향상을 나타내지 않고 있어서 학업 저성취학생들을 대상으로 하는 경우 프로그램 이수 후 학습을 지속할 수 있는 다양한 지원이 필요할 것으로 보인다. 


\section{2 제언}

본 연구의 결과를 토대로 학업 저성취 대학생들을 위한 교육적 제언은 다음과 같다.

첫째, 대학은 학습에 어려움을 겪는 학업 저성취 대학생들을 미리 파악하는 것이 필요하다. 학습에 대한 어려움을 겪는 학생들이 학사경고자가 되지 않도록 사전에 미리 에방하는 차원에서 학업에 어려움을 겪고 실제 학업에 저성취를 보이고 있는 학생에 대한 실제적인 현황 파악이 무엇보다 선제적으로 필요하다.

둘째, 학업 저성취의 원인을 분석하는 연구가 필요하다. 학업 저성취의 원인에 따라 지원되는 부분이 달라야 할 것이다. 학업 저성취의 원인은 학습 문제, 가정 문제, 심리 문제, 건강 문제 등 학생 개개인의 문제가 깊숙히 관여되어 있다. 따라서 학업 저성취의 원인을 파악하여 이들의 다양한 문제를 해결해 나가 수 있도록 다양한 지원이 필요하다.

셋째, 학업 저성취 학생들을 위한 다양한 프로그램을 운영할 필요가 있다. 학업 저성취의 원인별로 다양한 프로그램이 기획되고 운영되어야 한다. 진로집단상담 프로그램. 학업미루기 습관 바꾸기 프로그램, 학습전략 프로그램 등 다양한 주제로 프로그램이 운영되어야 한다. 특히 프로그램에 참여하는 학생들의 기대 및 요구사항, 학습의 구체적인 목표를 달성할 수 있도록 의견사항 등을 프로그램에 반영하여 운영할 필요가 있다.

넷째, 학업 저성취 대학생을 위한 프로그램은 단기성 보다는 지속성을 가지고 운영하여야 한다. 학업 저성취 학생들이 프로그램 이후 수 연계성 있는 프로그램의 운영이나 지속적으로 학습을 관리해주는 것이 필요하다. 전문상담원이나 학과멘토 등 학업에 지속적으로 도움을 줄 수 있어야 하며 외부협력기관과의 연계 지원이나 전공학습에 도움을 받을 수 있는 튜터링 프로그램 등이 연계 운영되어야 한다..

다섯째, 학업 저성취 대학생들을 위한 프로그램의 효과성을 높이기 위해서는 학업 저성취 대학생들을 위한 다양한 학습 동기 유인책을 동원할 필요가 있다. 성적장학금 지급이나 학점인정 등 학생들의 자발적 참여를 이끌어내어 결국에는 대학학습의 성공, 학사경고 탈출, 학사경고 재발 방지, 중도탈락 예방까지도 기대해볼 수 있다

여섯째, 학업 저성취 학생들을 위한 학생 요구별 학습지원이 더 세밀하게 마련될 필요가 있다. 학업 저성취 학생을 대상으로 한 프로그램은 자기주도학습능력 향상 프로그램 외에 학업 저성취 학생들의 요구사항을 수렴하여 요구별로 학업 저성취 학생들이 참여할 수 있는 프로그램들로 다양하게 운영되어야 할 것이다.

일곱번째, 학업 저성취자 대학생들을 위해서는 학습력을 향상시킬 수 있는 프로그램의 운영도 중요하지만 무엇보다도 학업 저성취 학생들을 위한 정서적 지지, 대학에서의 소속감, 전공교수와의 다양한 상호작용, 교우관계도 중요한 요인으로 작용한다. 따라서 대학구성원으로서 소속감을 형성할 수 있도록 멘토교수를 지정하여 대학 생활 내내 지속적으로 상호작용할 수 있도록 지원해주여야 한다.

마지막으로 학업 저성취 대학생을 예방 하기 위한 학사 저성취 학생 에측 모형을 개발하는 것이 필요하다. 예측모형으로 학업 저성취 학생이 발견되면 전문상담원과의 지속적인 학습 상담이나 멘토링 프로그램을 활용하여 체계적으로 관리할 필요가 있다.

\section{References}

[1] Kim Na-mi, Kim Hyoe-won, The Verification of Effectiveness of a Self-directed Learning Program through a Peer- 
Mentoring System of College Students on Academic Probation, The Journal of Learner-Centered Curriculum and Instruction (2015), Vol.15, No.12, pp.875-900, UCI : G704-001586.2015.15.12.021

[2] M. S. Knowles, Self-diredted learning: A Guide for learners and teacher, Chicago: IL Follet Publishing Company, (1975)

[3] Lim Irang, The Effects of Academic Self-Efficacy and Cognitive Strategy on the Academic Adaptation of Underachieving College Students: Moderated Mediation Effect of Social Support, Forum for Youth Culture, (2019), Vol.60, pp.117-146. DOI: 10.17854/ffyc.2019.10.60.117

[4] C. J. Fong, J. M. Krause, Lost confidence and potential: a mixed methods study of underachieving college students' sources of self-efficacy, Social Psychology of Education, (2014), Vol.17, No.2, pp.249-268. DOI: 10.1007/s11218013-9239-1

[5] Gang Soon-Wha, Lee Eun-kyoung, Yang Nan-mee, A study About Developing the Academic Support System Through an Analysis of the Characteristics Between the High Achievers and Underachievers in their academic performance in the University, The Korean Journal of Counseling and Psychotherapy (2000), Vol.12, No.2, pp.221-242

[6] Yoon So-Jung, The Development and Effects of a Preventative Learning Consultation Program for University Underachievers, Journal of fishries and marine sciences education, (2013), Vol.25, No.3, pp.643-660. DOI: 10.13000/JFMSE.2013.25.3.663

[7] Park Duk-hee, Analyzing the Effects of One-to-One Learning Community for College Undergraduate Students on Low Achievement, The Journal of Learner-Centered Curriculum and Instruction, (2017), Vol.17, No.6, pp.375-402. DOI : 10.22251/jlcci.2017.17.6.375

[8] Jin Sung-Hee, Im Ko-woon, Kim Tae-Hyun, Educational Effectiveness of Academic Improvement for Undergraduate Low Achievers, Asian Journal of Education, (2019), Vol.20, No.3, pp.671-694. DOI: 10.15753/aje.2019.09.20.3.671

[9] Kim Na-mi, Kim hyoe-won, Bak Wan-sung, Effects of a Resilience Improvement Program Applying a Peer-Mentoring System on College Students on Academic Probation, The Journal of Yeolin Education, (2014), Vol.22, No.1, pp.391412. UCI: G704-001282.2014.22.1.020

[10] Joo Young-A, Jung hee-jin, Whang Sun-hee, Kim Young-hye, Study on the Effects of a Group Counseling Program to Enhance Self-Determination and Stress Coping Strategies for the Academically Underachieving College Students, The Journal of Learner-Centered Curriculum and Instruction, (2013), Vol.13, No.2, pp.85-115. UCI: G704001586.2013.13.2.012

[11] H. Seirup, S. Rose, Exploring the effects of hope on GPA and retention among college undergraduate students on academic probation, Education Research International, (2011), pp.1-7. DOI: 10.1155/2011/381429 